\title{
Comparison between ESR and C-Reactive Protein(CRP) as a Marker of Disease activity in Patients with Rheumatoid Arthritis
}

\author{
Ali M.E. Yousef ${ }^{1}$, Fatemah A. Elshabacy ${ }^{2}$, Sherry K. Abdelrahman ${ }^{2}$, Taghred F. Mohamed ${ }^{2}$ \\ Departments of Internal Medicine ${ }^{1}$, Rheumatology and Rehabilitation ${ }^{2}$, Benha Teaching Hospital; Egypt
}

\begin{abstract}
Background: Laboratory tests such as the erythrocyte sedimentation rate(ESR) and C-reactive protein (CRP) have been used as markers of inflammation and disease activity in rheumatoid arthritis (RA), although there is still no clear consensus on when to use one, the other, or both. Objective: To determine ESR and CRP values in active RA patients and their correlation with different parameters of disease activity. Patients and Methods: Eighty patients with active RA, attending rheumatology department at Benha Teaching Hospital, diagnosed according American College of Rheumatology (ACR) and European League Against Rheumatism (EULAR) revised criteria were included. The patients' tender and swollen joint counts were calculated. Laboratory investigations were done including ESR by Westergren method and CRP by ELISA method, assessment of disease activity using DAS28 score. Results: All patients showed disease activity at time of the study, their DAS28 score was ranged from 2.9 to 7.5 (Mean \pm SD $5.42 \pm 1.1$ ). The values of ESR was ranged from 10 to $150 \mathrm{~mm} / \mathrm{h}$ in first hour (Mean \pm SD $52.9 \pm 33.9$ ). CRP was positive in 54 patients but negative in $26(67.5 \%$ versus 32.5\%), the CRP values was ranged from 0.6 to $65 \mathrm{mg} / \mathrm{dl}(\mathrm{Mean} \pm \mathrm{SD}$ 18.1 \pm 15.8 ). There were statistically significant correlation between DAS28 values and number of tender \& swollen joints and ESR values (P-value was <0.001, <0.001, 0.004 respectively), on the other hand there was no significant correlation between DAS28 patients age and CRP values ( $\mathrm{P}$ value was $0.60,0.18$ respectively). Conclusion: our study suggests that CRP is not a viable marker in the clinical setting to monitor inflammatory activity in the RA patient, and that the role of and dependence on CRP as a marker of inflammation in RA patients in everyday practice should be reevaluated. [Egypt J Rheumatology \& Clinical Immunology, 2015; 3(1): 77-81]
\end{abstract}

\section{INTRODUCTION}

\begin{abstract}
Rheumatoid arthritis (RA) is a chronic systemic disease, usually manifesting as inflammation of multiple joints. It is characterized by a number of extra-articular manifestations, including rheumatoid nodules, vasculitis, heart or lung disease, anemia, and peripheral neuropathy. Although the cause of RA is unknown, it is generally considered an autoimmune disease. At present, no single test of disease activity in RA is effective because RA may cause various kinds of symptoms and signs ${ }^{1}$.

Different measures are used for evaluating disease activity in rheumatoid arthritis (RA). Laboratory tests such as the erythrocyte sedimentation rate (ESR) and C-reactive protein (CRP) have been an integral part of the clinicians' repertoire for many years, used as markers of inflammation, although there is still no clear consensus on when to use one, the other, or both ${ }^{2}$. Among these tests CRP had become the more preferred serological marker for evaluating acute disease activity ${ }^{3}$.
\end{abstract}

For Correspondence: prof.aliyousef@yahoo.com
Disease activity score (DAS) and its derivatives use ESR or CRP as part of their score and as such they have found increased use and discussion regarding their role in disease activity assessment. Because of the way these indices are calculated, ESR and CRP may play a disproportionately significant role in the overall score ${ }^{4}$.

Monitoring of RA patients is difficult in some cases as up to $40 \%$ of patients have normal ESR or $\mathrm{CRP}$ at presentation ${ }^{5}$, which makes it hard to use these measures in close to half of active, treatment requiring RA patients. The quantitative usefulness of ESR versus CRP has been evaluated in many studies with no clear consensus. ESR and/or CRP are part of the American College of Rheumatology (ACR) core data set for measuring disease activity in RA and have been used in clinical trials as the main laboratory marker of disease activity in $\mathrm{RA}^{2}$.

\section{Aim of The Study}

The aim of this study was to determine ESR and CRP values in active RA patients and their correlation with different parameters of disease activity. 


\section{PATIENTS AND METHODS}

The study was carried out on eighty patients with active RA, attending rheumatology department at Benha Teaching Hospital these patients were diagnosed according American College of Rheumatology (ACR) and European League Against Rheumatism (EULAR) revised criteria ${ }^{6}$.

The patients were subjected to thorough general and articular examination. Tender and swollen joint counts were calculated. Laboratory investigation were done including ESR by Westergren method ${ }^{7}$ and CRP by ELISA method ${ }^{8}$, assessment of disease activity using DAS28 score? .

\section{Statistical Analysis:}

The collected data were tabulated and analyzed using SPSS version 16 soft ware (Spss Inc, Chicago, ILL Company). Categorical data were presented as number and percentages while continuous data were expressed as mean, standard deviation and range. Spearman's correlation coefficient (rho) and Man Whitney U test were used as tests of significance. The accepted level of significance in this work was stated at $0.05(\mathrm{P} \leq 0.05$ was considered significant $)$

\section{RESULTS}

Eighty RA patients were included in this study; they were seventy two females and eight males. Their ages ranged from 25 to 69 years (Mean \pm SD; 47.7 \pm 11.3 ). All patients showed disease activity at time of the study, their DAS28 score was ranged from 2.9 to 7.5 (Mean \pm SD 5.42 \pm 1.1 ). Comparison between male and female patients as regards DAS28, showed that there was statistically significant differences between both groups $(\mathrm{P}=0.031)$.

The values of ESR was ranged from 10 to $150 \mathrm{~mm} / \mathrm{h}$ in first hour (Mean \pm SD 52.9 \pm 33.9$)$. CRP was positive in 54 patients but negative in $26(67.5 \%$ versus $32.5 \%$ ), the CRP values was ranged from 0.6 to $65 \mathrm{mg} / \mathrm{dl}($ Mean \pm SD 18.1 \pm 15.8$)$.

DAS28 values were correlated with variable clinical and laboratory data in the studied group, there were statistically significant correlation between DAS28 values and number of tender \& swollen joints and ESR values ( $\mathrm{P}$ value was $<0.001,<0.001,0.004$ respectively), on the other hand there was no significant correlation between DAS28 patients age and CRP values ( $\mathrm{P}$ value was $0.60,0.18$ respectively).

Table 1. Basic characters of the studied sample.

\begin{tabular}{|c|c|c|c|}
\hline & iable & No. $(\mathrm{N}=80)$ & $\%(100.0)$ \\
\hline \multirow{3}{*}{ Gender } & Male & 8 & 10.0 \\
\hline & Female & 72 & 90.0 \\
\hline & Mean \pm SD & Min. & Max. \\
\hline Age & $47.7 \pm 11.3$ & 25 & 69 \\
\hline TJC & $13.8 \pm 9.6$ & 0 & 28 \\
\hline SJC & $2.15 \pm 4.9$ & 0 & 22 \\
\hline DAS & $5.42 \pm 1.1$ & 2.9 & 7.5 \\
\hline ESR & $52.9 \pm 33.9$ & 10 & 150 \\
\hline \multirow{3}{*}{ CRP } & $18.1 \pm 15.8$ & 0.6 & 65 \\
\hline & Positive & 54 & 67.5 \\
\hline & Negative & 26 & 32.5 \\
\hline
\end{tabular}

$\overline{T J C}$ tender joint count, $\boldsymbol{S J C}$ swollen joint count, $\boldsymbol{E S R}$ erythrocyte sedimentation rate, $\boldsymbol{C R P}$ c-reactive protein.

Table 2. Comparing DAS among males and females

\begin{tabular}{llcccc}
\hline & Sex & N & Mean \pm SD & "Z" of MWU & P \\
\hline \multirow{2}{*}{ DAS } & Male & 8 & $6.32 \pm 1.224$ & 2.15 & $0.031^{*}$ \\
& Female & 72 & $5.32 \pm 1.053$ & & \\
\hline
\end{tabular}

$\overline{D A S}$ disease activity score 
Table 3. Correlation between DAS and the studied variables.

\begin{tabular}{lcc}
\hline & \multicolumn{2}{c}{ DAS } \\
\cline { 2 - 3 } & rho & P \\
\hline Age & -0.06 & $0.60 \mathrm{NS}$ \\
TJC & 0.839 & $<0.001 * * \mathrm{HS}$ \\
SJC & 0.545 & $<0.001 * * \mathrm{HS}$ \\
ESR & 0.316 & $0.004 * \mathrm{~S}$ \\
CRP & 0.151 & $0.18 \mathrm{NS}$ \\
\hline
\end{tabular}

$\overline{\boldsymbol{T J C}}$ tender joint count, $\boldsymbol{S J C}$ swollen joint count, $\boldsymbol{E S R}$ erythrocyte sedimentation rate, $\boldsymbol{C R P}$ c-reactive protein, $\boldsymbol{N S}$ non significant, $\boldsymbol{S}$ significant, $\boldsymbol{H} \boldsymbol{S}$ highly significant.

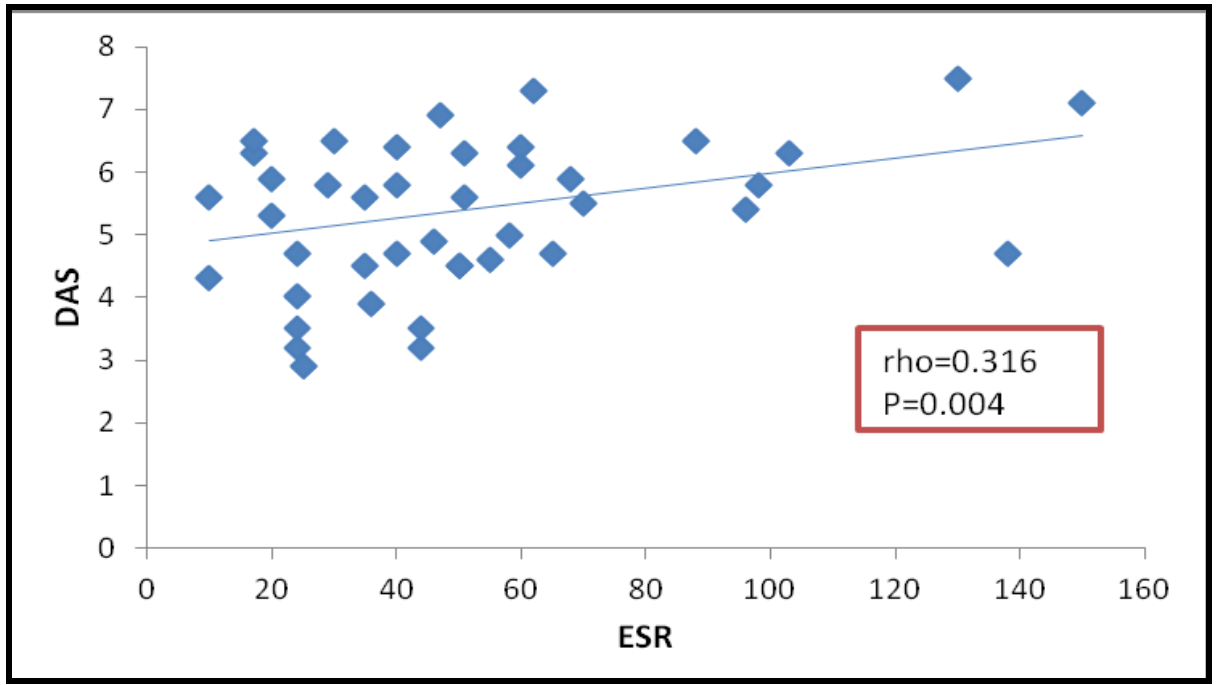

Figure 1. Correlation between DAS28 and ESR.

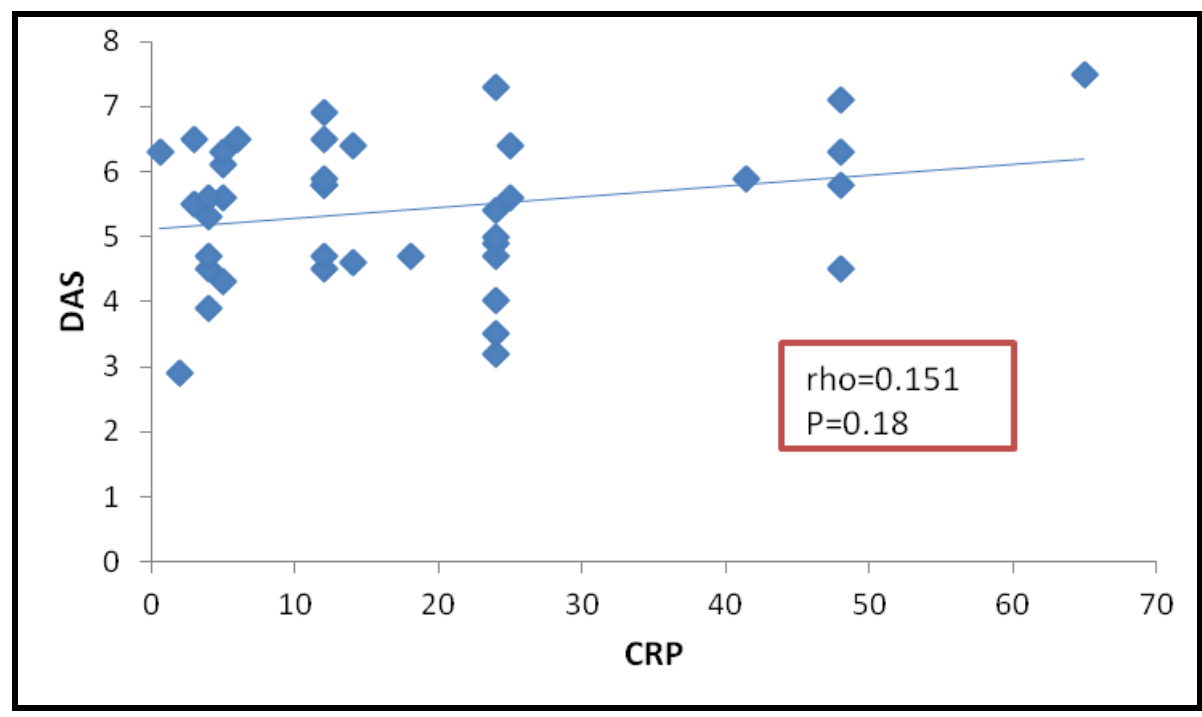

Figure 2. Correlation between DAS28 and CRP. 


\section{DISCUSSION}

ESR and CRP originally were used to assess activity and response to treatment in inflammatory diseases such as RA $^{10}$.

In this study we aimed to determine ESR and CRP values in active RA patients who attending rheumatology department Benha teaching hospital and their correlation with different parameters of disease activity.

Eighty patients with active RA were included in the study, they were seventy two females and eight e males. Mean DAS among patients was 5.24 \pm 1.1 ; mean ESR and CRP were $18.1 \pm 15.8$ and $52.9 \pm 33.9$ respectively.

ESR was statistically correlated with DAS of the RA patients whereas CRP values and DAS were not $(\mathrm{P}=0.004,0.18$ respectively). At the same time there was no significant correlation between ESR and CRP among the included RA patients. These results coincide with a study published at 2010; it stated that ESR and CRP cannot be used in the diagnosis of RA because $45 \%$ of patients may have normal serum levels at presentation, although these values represent part of the diagnostic syndrome or classification criteria sets ${ }^{11}$.

Longitudinal study conducted between 1980 and 2004 analyze erythrocyte sedimentation rate, Creactive protein, and rheumatoid factor (RF) tests in 2 databases of consecutive patients with rheumatoid arthritis (RA) over 25 years, in Finland and the USA, a majority of patients with RA seen had abnormal ESR, CRP, or RF. However, more than $37 \%$ of patients had ESR $<28 \mathrm{~mm} / \mathrm{h}$, normal CRP, or all negative RF tests. Similarities of laboratory test data at 2 sites on different continents with different duration of disease suggest generalizability of the findings. Normal ESR, CRP, and RF are seen in a substantial proportion of patients with RA at this time ${ }^{12}$.

On the other hand, JEFFREY et al (2012) demonstrated a significant association between the MBDA (multi-biomarker disease activity) and the DAS28-CRP in heterogeneous groups of RA patients with diversity in autoantibody status, disease activity, and RA therapy in RA patients receiving care in multiple clinical centers ${ }^{13}$.

Absence of significant correlation between CRP and disease activity in the current study disagreed with a previous study which ensure that serum CRP, among the various RA patients, is the most useful biochemical marker for evaluating the disease activity of patients with $\mathrm{RA}^{1}$. Some authors reported that ESR and CRP values were weakly correlated with disease activity measures. These data suggested that another look at the role of ESR and CRP as markers of inflammation in RA patients seen in routine care may be in order ${ }^{2}$.

Despite the elevation of individual components of the Clinical Disease Activity Index (CDAI) (tender and swollen joint counts and patient and physician global assessment), some patients with active RA may have normal erythrocyte sedimentation rate (ESR) and/or C-reactive protein (CRP) levels and thus fail to meet entry criteria for clinical trials ${ }^{14}$.

Existence of RA patients with depressed CRP concentrations caused by carrying low-CRPassociated genetic variants must be taken into account when this test is used universally ${ }^{11}$.

ESR is a reflection of Fibrinogen level in the blood, so conditions that elevate fibrinogen, even if they are not necessarily considered inflammatory, can raise ESR. These include pregnancy, diabetes, endstage renal disease, and heart disease. Major increases in the concentration of a single molecular species, such as a monoclonal immunoglobulin in multiple myeloma, also cause increased sedimentation ${ }^{10}$. However, microcytosis, polycythemia, and abnormally shaped RBCs (e.g., sickle cells, spherocytes) hinder aggregation and lower the $\mathrm{ESR}^{15}$.

The ESR is elevated, in obesity, as is CRP, presumably as a result of IL-6 secretion by adiposities ${ }^{16}$.

In conclusion, we suggest that CRP is not a viable marker in the clinical setting to monitor inflammatory activity in the RA patient, and that the role of and dependence on CRP as a marker of inflammation in RA patients in everyday practice should be re-evaluated.

[Disclosure: Authors report no conflict of interest]

\section{REFERENCES}

1. Kadir Yildirim, Saliha Karatay,Meltem Alkan Melikoglu, et al. (2004): Associations between Acute Phase Reactant Levels and Disease Activity Score (DAS28) in Patients with Rheumatoid Arthritis. Annals of Clinical \& Laboratory Science 34: 423-426.

2. Keenan R.T, Swearingen C.J, Yazici Y (2008): Erythrocyte sedimentation rate and Creactive protein levels are poorly correlated with clinical measures of disease activity in rheumatoid arthritis, systemic lupus erythematosus and osteoarthritis patients. Clinical and Experimental Rheumatology; 26: 814-819.

3. Skogh T, Gustafsson D, Kjellberg M and Husberg $M$ (2003): Twenty eight joint count disease activity score in recent onset rheumatoid arthritis using $\mathrm{C}$ reactive protein instead of erythrocyte sedimentation rate. Ann Rheum Dis.; 62: 681-82 
4. Gardiner PV, Bell AL, Taggart AJ et al. (2005): A potential pitfall in the use of the Disease Activity Score (DAS28) as the main response criterion in treatment guidelines for patients with rheumatoid arthritis. Ann Rheum Dis.; 64: 506-7.

5. Wolfe F and Michaud K (1994): The clinical and research significance of the erythrocyte sedimentation rate. J Rheumatol 1994; 21: 1227 37.

6. Aletaha D., Neogi T., Silman A.J., Funovits J. et al. (2010): 2010 rheumatoid arthritis classification criteria: an American College of Rheumatology/European League Against Rheumatism collaborative initiative study . Ann. Rheum . Dis.; 69(9): 1580-8.

7. Westergren A (1957): "Diagnostic tests: the erythrocyte sedimentation rate range and limitations of the technique". Triangle 3(1): 20-5.

8. Macy EM, Hayes TE, Tracy RP.(1997): Variability in the measurement of C-reactive protein in healthy subjects: implications for reference intervals and epidemiological applications. Clin Chem; 43:52-58.

9. Prevoo M.L., Van't Hof et al., (1995): Modified disease activity scores that include twenty -eight joints counts.Arthritis. Rheum; 38: 44-48.

10. Saxena A and Cronstein B (2013): Acute Phase Reactants and the Concept of Inflammation : Kelley's Textbook of Rheumatology, Ninth Edition. Philadelphia Saunders Elsevier Inc :818826.
11. Rhodes B, Merriman ME, Harrison A, et al. (2010): A genetic association study of serum acute-phase C-reactive protein levels in rheumatoid arthritis: implications for clinical interpretation, PLoS Med 7:1000341

12. Sokka T, and Pincus T (2009): Erythrocyte sedimentation rate, C-reactive protein, or rheumatoid factor is normal at presentation in 35$45 \%$ of patients with rheumatoid arthritis seen between 1980 and 2004: analysis from Finland and the United States. J Rheumatol 36:1387-1390.

13. Jeffrey R. Curtis, Annette H. et al. (2012) :Validation of a Novel Multibiomarker Test to Assess Rheumatoid Arthritis Disease Activity Arthritis Care \& Research , 64 : pp 1794-1803.

14. Kay J et al (2014) :Clinical disease activity and acute phase reactant levels are discordant among patients with active rheumatoid arthritis. Arthritis Research \& Therapy, 16:R40 .

15. Vajpayee N, Graham SS and Bem S (2007) : Basic examination of blood and bone marrow. In McPherson RA, Pincus MR, editors: Henry's clinical diagnosis and management by laboratory methods, ed 21, Philadelphia, Saunders Elsevier, pp 465-466

16. Bastard JP, Maachi M, Van Nhieu JT, et al. (2002): Adipose tissue IL-6 content correlates with resistance to insulin activation of glucose uptake both in vivo and in vitro, J Clin Endocrinol Metab 87:2084-2089. 